\title{
THE DOMESDAY BOOK : VISUALIZATION TOOLS TO EXPLORE IDENTITY AT THE START OF THE SECOND MILLENNIUM
}

\author{
Martyn Jessop \\ Centre for Computing in the Humanities \\ King's College London \\ Strand \\ London, WC2R 2LS \\ United Kingdom \\ Martyn.jessop@kcl.ac.uk
}

\begin{abstract}
Exploring patterns of settlement and land ownership have always been of interest to the historian but could these patterns be used, as it were, 'in reverse' not simply to display what is already known but to resolve gaps, uncertainties and ambiguities in the historical record? It was the nature of life in the eleventh century that individuals were rarely named uniquely and were frequently known by different names in different circumstances. Could visualization tools be used to resolve these frequently obscure and ambiguous identities recorded in the Domesday Book?
\end{abstract}

\section{INTRODUCTION}

The confirmation of our identity has become an almost daily requirement of modern life, whether through the use of bank cards in ATM cash machines or the possession of a passport carrying encoded biometric data. These have obvious value but others, such as the requirement to carry a photo identity card when one wishes to commute by train regularly are more invasive. The State gathers information that becomes associated with identity and is stored in rigid formats, such as those of modern census returns, recording who we are and how we live. Commercial organisations monitor our purchases and build up a profile of our socio-economic identity. In these cases our identity is rigidly defined by our surname, forename, date of birth, address, mother's maiden name and so forth in a way that has now extended beyond our national borders to become a global entity. This simple defining information is considered so unique that unauthorised possession of it allows others to access our savings as well as load us with debt for loans we did not take out; the theft of material goods can be achieved through the misappropriation of the information that defines our formal identity. In the complexity of life in modern society the individuality of our identity has become more important than ever before with the information that defines this uniqueness being paramount.

However, identity has not always been defined so decisively, even for the elites of the social order. A current project at the Centre for Computing in the Humanities at King's College London, using the Domesday Book as source data, is providing an opportunity to explore the problems of identifying individuals living nearly a thousand years ago at the beginning of the second millennium; a time when there was no standard 
way of referring to an individual even by name and only the bare beginnings of the organisation of a state at a national level.

The information recorded within the Domesday Book is largely numerical and should therefore lend itself to computational analysis. The economic and social historian can glean valuable data on arable exploitation and income from landholding as well as quantifying the population in terms of social classes. But there is far more to this data than can be revealed by quantitative analysis. The data also contains evidence of the procedures of administration and patterns of shifts in power and influence. Much of this requires an understanding of the status of particular individuals before and after the conquest. The issues of uncertain or ambiguous identities present in the document impede the investigations at this level and missed or miss-identified groupings of names associated with a particular individual may skew the analysis of the data more generally. However, there are ways in which visualizations of the data in spatial terms can be used to resolve, clarify, or reveal the true identities and power of the men and women at the centre of English society over a thousand years ago.

\section{DOMESDAY BOOK}

The Norman invasion of 1066 plunged England into a period of intense social upheaval. During his later years King William came under threat from a number of sources. Chief among these were King Canute IV of Denmark and King Olaf III of Norway. The policy of the time was to buy off these two aggressors with a fund called the Danegeld. The most probable reason for the compilation of the Domesday Book was to determine how much tax William was receiving and therefore the level of Danegeld that could be paid. The book records, for each settlement in England, its monetary value and any dues owed to the King. The fiscal information is shown at the time of the survey, before Domesday, and from before 1066. It is a complete record of lands held by the king and by his tenants and of the resources that went with those lands. Its compilation formalised a process of transition by recording which manors rightfully belonged to which estates. It ended years of confusion resulting from the gradual dispossession of the Anglo-Saxons by the Normans. It is also a snapshot of the feudal hierarchy showing the identities of the tenants-in-chief who held their lands directly from the King, and of their tenants and under tenants. Many of the details of the changes that occurred are recorded in the Domesday Book but in a way that would be quite alien to a modern social scientist or geographer. The information recorded within it is resistant to the techniques that would be applied to modern social surveys and census data. The inconsistencies and ambiguity present defy modern quantitative methods and standard digital tools. However, the data is typical of that used by historians and other researchers within the humanities and so form an important case study. What is required is a more fluid qualitative method that is closer to arts and humanities methodology than that of the social scientist.

Domesday records the nature and structure of society in 1086 but also tells us of the sweeping changes that had occurred in the intervening twenty years since the conquest. The fundamental problem is one of establishing the identity of individuals across the whole country. A single person frequently held land in more than one county but might 
be referred to in each case by different identities. These are not just variations in spelling but also in title and the way an individual is known, by a byname such as 'the Wolf', or a number of other names and titles of differing purposes. What one is faced with is a very detailed, colossal puzzle which requires ingenuity and creative thought to unravel. Textual methods are of only limited value but spatial analysis and visualization offer significant advantages. Existing Geographical Information System (GIS) tools might be applied but the purpose of this project is to develop digital visualization tools that will allow anyone, whether professional historian or interested amateur, to explore the content of the Domesday Book via a visualization tool that is sufficiently versatile (and free!) but easy to use to tackle information that resists the 'traditional' scientific methods of GIS. The project has scope for fresh thinking about visualization tools that cross disciplinary boundaries and open access to digital resources for analysis and study by new audiences. The experiences have value that extends far beyond the current application and have informed our general views on a more fluid, versatile approach to the visualization of qualitative and quantitative data in the arts and humanities.

\section{RESOLVING IDENTITY THROUGH VISUALIZATION}

How can visualization tools be used to reveal new interpretations of data that has already been studied for many hundreds of years?

There are three characteristics that can be utilized by visualization techniques to help resolve uncertain or ambiguous identities:

- Proximity

- Patterns

- Succession

These are three useful starting points but research with the visualization tool is still at an early stage. The essence of visualization is that there is an element of playful experimentation which may reveal further characteristics which can also be used as the work progresses.

\section{Proximity}

The most obvious spatial relationship found in land holdings is that a particular individual will tend to hold parcels of land that are clustered close together. If there is any doubt about the true identity of someone, a map of a known individual's landholdings and those of the ambiguous person may show the latter's holdings to be grouped with the known individual and thus suggest that the are one and the same person.

\section{Patterns}

There are a variety of possible patterns that can be revealed though visualization. The first is the size of estates; the nature of landholding at the time was that individuals who controlled large parcels of land tended to have only other large parcels (and vice versa). By searching for and displaying the distribution of estates of a certain size range 
belonging to particular individuals it is possible to find relationships (or an absence of them) that lead the viewer to question current interpretations of the data.

Experimentation with maps of different aspects of the data or of data revealed by speculative queries of combinations of particular variables may also reveal previously unsuspected relationships.

\section{Succession}

One of the many interesting aspects of the society recorded in Domesday is that it displays patterns of continuity and change across the upheavals of the post-conquest period. Although there was a massive change in the 'persons' involved, the social 'structures' appear to have remained the same. Post-conquest lordships often followed in the footsteps of the pre-conquest ones. The new Norman lords where frequently assigned lands in several different counties that were previously assigned to a single Saxon lord. For example the lands of the Anglo-Saxon Lord Geoffrey de Mandeville all passed to Asgar the Staller after the conquest. This process was not restricted to the upper echelon of society and the same process applies as one moves down the hierarchy. Thus the lands held by men and women commended to an Anglo-Saxon lord were passed to that lord's Norman successor and subsequently to his subtenants. These close links between the two power structures and the close similarity of the status of posts between Anglo-Saxon and Norman hierarchy can be used to resolve issues of identity. In principle, the patterns of landholding before and after the conquest should be similar with only the 'persons' involved changing not the geographical distribution and patterns of holdings. By comparing the patterns for particular individuals before and after the conquest it is possible to find anomalies that may hint at miss-identification of identity in existing interpretations.

This is an area where a visualization tool is extremely valuable as it is possible to pull out quite complex sets of possible relationships and display them quickly and easily thus encouraging a 'let's see if ....' style of exploration.

\section{Implications for visualization}

The above discussion identifies the items of data from Domesday that are of value in the visualization; names, titles, the location of the estates, and items that identify their size or value. How does this shape the functionality of the visualization tool?

When considering the production of maps one tends to think of gathering information on boundaries, rivers, topography and transport networks but in this case none of these things are of interest (or even of secondary interest). We are dealing purely with the relationships between locations and the comparison of different patterns of location; the relationships of them to other geographical features are largely irrelevant. What is required is basically a set of dots showing the locations: a symbol map or proportional symbol map. The dots may be differentiated by colour or size and that differentiation may display differences in holdings by individuals, the size of the holding or its fiscal value. 


\section{VISUALIZATION, SPATIAL DATA AND THE HUMANITIES SCHOLAR}

The humanities scholar who wishes to use spatial data in his or her research faces a number of problems. Visual methodology is not widely applied in the predominantly textual research of the humanities scholar and so the methods are unfamiliar. The digital tools that are currently in use for mapping and geographical information systems (GIS) were designed for planners, land use studies, earth scientists and the social sciences. They are expensive, over-complex, hard to use, and ill-equipped to cope with the very different nature of historical sources [2].

Digital tools may be used to investigate all of the relationships that were described earlier as being important to an exploration of identity but they can be limited in what they can do with historical data such as that in Domesday. The tools were developed for disciplines where very detailed and highly precise data is collected in the field (for example, geography, social sciences, planning, land-management). The source data that records the past is rarely so detailed and is frequently sparse, imprecise and ambiguous. A researcher working on social phenomena today would probably find ways around these problems by carefully designed data collection methods, collecting more data or using geo-statistical techniques that would 'process out' the problems. However, it is often the ambiguities and anomalies that are of greatest interest to the historian; in this case they are not a 'problem' but rather a key aspect of the study of the data so ways must be found of accommodating them in the digital tools used by historians or other humanities scholars.

Fortunately the pattern of administration and settlement at the end of the AngloSaxon period has persisted until the present day (for example, the county boundaries of 1086 were in use almost without change until the review of administrative boundaries in 1974). Anglo-Saxon place names can be linked to modern place names and precise geographical locations obtained. The quantitative data (area, fiscal value, number of cattle etc.) is clear. The problems therefore arise with the identification of individuals and as far as I am aware this project is the first to attempt to use visualizations of the spatial data to resolve them.

\section{THE CHOICE OF VISUALIZATION TOOLS}

The project started off by experimenting with Google maps. This allowed us to display point locations and gave visually appealing background maps (satellite images or modern road maps etc.) but the modern mapping was felt to be inappropriate and the database searching and mapping styles that we required would have required substantial additional programming effort. The capabilities that are required are simple but still approach those expected of a GIS; the ability to search a database via queries that allow some sophistication of interrogation and the ability to plot the results of these queries on proportional symbol maps with some form of boundary data. These characteristics are likely to be found only in dedicated mapping applications. However, the ability to access and display the data via the web is of considerable value and so other sources of web-mapping were explored. The final solution was to provide two alternative but complementary visualization tools; an online mapping resource for simple web-based 
mapping and a desktop GIS file viewer that can be downloaded with a set of data files for more sophisticated exploration.

There are a number of difficulties facing historians in their use of GIS, many of which are discussed in a paper by the author [2]. These all impinged upon this project but I will focus on a more pragmatic subset of issues here:

- The high cost of software

- The complexity of the software and the steep learning curve associated with it

- The level of cartographic knowledge required.

- Cost and difficulty of obtaining the underlying digital maps

- Cost and difficulty of digitising source data.

The software costs of a full mapping or GIS application are high and the sophistication of the software is far in excess of what a historian requires in order to explore the Domesday data. The first hurdle is therefore the software itself, both in terms of cost and the amount of learning time required to overcome the complexity of the software and of the cartographic process. Furthermore, when using a mapping tool or GIS, how does one disseminate research results which are embedded in GIS databases or other digital objects? Will everyone who one wishes to discuss the work have to have gone through the same time consuming and costly process as you? The desktop solution provided with the Domesday data overcomes all these problems by being free (for non-commercial use) and by providing only a simple (but still very powerful) set of functions. It is therefore accessible to all. The software, ArcExplorer ${ }^{\mathrm{TM}}$ is produced by ESRI ${ }^{\mathrm{TM}}$ the company who produce market leading GIS software.

For the Anglo-Saxonist, few of the features depicted on modern maps are relevant to the period being studied. However, what level of detail is actually required in the underlying base map when what one is really interested in are the relationships 'between' locations in the data rather than their relationship to modern day features? The project provides only county boundaries, rivers, and simple topography. In practice the latter two are rarely used and the county boundaries are only there as a psychological 'prop', something familiar to tie the visualization to. The visual material that matters is the patterns of locations.

When contemplating the use of GIS software and data there is a danger of falling into a mindset that seeks a level of complexity or sophistication that is completely unnecessary simply because this is how the methodology is presented by researchers in other fields. Although care is still required over the basic cartography, the approach advocated here greatly simplifies the acquisition, management, and visualization of the underlying map data. Many researchers are introduced to GIS as a digital tool rather than as an approach to scholarship. Gregory and Ell comment that the researcher using GIS should be asking 'what are the geographical aspects of my research question?' rather than 'what can I do with my dataset using this software?' [3]. The relative ease with which ArcExplorer can be used and integrated with other commonly used tools such as Microsoft Word, Access or Excel helps the scholar to regard it as just another research tool rather than placing it on a pedestal. The excellent level of support provided 
for ArcExplorer by ESRI helps this process greatly. There is a very good tutorial, materials to support its use in teaching, and support materials for allied areas of study such as cartography.

Another key factor for humanities users is that the software is available on both Mac and Windows platforms with the same interface.

\section{CONCLUSIONS}

The project is focused upon an iconic historical document, widely known to the general public and scholar alike. Data sets have been derived from it before, for example the excellent Domesday Explorer project by John Palmer [4] but the focus has not been on visualization. Digital scholarship performed on Domesday data sets has the potential to explore how the quantitative methods of the social sciences can be applied to $11^{\text {th }}$ Century England. However, this project goes further than that to explore issues of data interoperability and, most significantly, digital visualization. The digital tools present here allow the results and supporting data sets to be disseminated without encountering the barriers normally experienced by the 'casual' user of GIS.

In this first phase of the project the visualization tools and the associated data sets are currently being trialled with a group of selected users. The style of the visualizations has moved away from 'traditional' maps used simply for the presentation of the final results of scholarship to more dynamic tools for exploring it interactively. The visualizations are stripped of extraneous geographical information and the researcher focuses entirely upon the visual relationships within the image - patterns of dots of varying size and colour. The next step will occur as the tools are used to explore the data on a larger scale; are there other ways to visualize this information that could be developed to gain fresh insights into the content despite it being subject to many years of scholarly study already?

\section{ACKNOWLEDGEMENTS}

The author wishes to thank the following for their collaboration in the work which produced this paper; Stephen Baxter (History Department, King's College London), Hafed Walda (CCH, King's College London), Peter Rose $(\mathrm{CCH}$, King's College London), John Bradley (CCH, King's College London), Payman Labbaf (CCH, King's College London), Simon Mahony (CCH, King's College London).

\section{References}

[1] MCKIE, R. and THORPE,V. Digital Domesday book lasts 15 years not 1000. Guardian, March 3 ${ }^{\text {rd }}, 2002$.

[2] JESSOP, M. The inhibition of geographical information in digital humanities scholarship. Literary and Linguistic Computing, Volume 23, No. 1, 2008. Oxford : Oxford University Press.

[3] GREGORY, I. and ELL, P. Historical GIS : technologies, methodologies, and scholarship. Cambridge : Cambridge University Press, 2007.

[4] PALMER, J. Domesday Explorer. http://www.domesdaybook.net/ 